\title{
Effect of some precursor characteristics on the porous texture of activated carbon fibres prepared form Nomex aramid fibres
}

(Microporous and Mesoporous Materials, 41, 319-321, 2000)

M. C. Blanco López, S. M. Villar-Rodil, A. Martínez-Alonso, J. M. D. Tascón

Instituto Nacional del Carbón, CSIC, Apartado 73, 33080 Oviedo, Spain.

\begin{abstract}
The influence of some characteristics of Nomex [poly ( $m$-phenylene isophtalamide)] fibres on the porous texture of activated carbon fibres (ACFs) prepared from them by pyrolysis and $\mathrm{CO}_{2}$ activation has been comparatively analysed. The features studied were the degree of crystallinity and the presence of dying additives on the precursor. The obtained ACFs were characterised by $\mathrm{N}_{2}(77 \mathrm{~K})$ and $\mathrm{CO}_{2}(273 \mathrm{~K})$ adsorption, and X-ray diffraction. Results show that the texture developed is mainly related to the degree of burn-off (BO) achieved. Crystallinity differences or presence of carbon black dye in the precursor originated little differences in porous texture, the main ones appearing at low and high BOs.
\end{abstract}

Keywords: Activated carbon fibres; Carbon dioxide adsorption; Microporosity; Nitrogen adsorption; Nomex.

The porous texture of activated carbon fibres (ACFs) is closely related with the properties of their precursors and the treatments undergone by them. Thus, highly crystalline aramid fibres originate microporous ACFs with narrow porosity distributions [1-5], whereas low crystallinity precursors, such as rayon, lead to ACFs with a wider pore 
size distribution [6]. As for the effects of textile and other treatments, cotton mercerisation favours the creation of mesoporosity in ACFs derived from it [7], while addition of carbon particles produces the same effect on ACFs from polyacrylonitrile [8] (thus, dyeing textile fibres with carbon black could have a similar effect).

The aim of this work was to compare the porous texture of ACFs prepared from Nomex [poly ( $m$-phenylene isophtalamide)] with different degrees of crystallisation and with and without dyeing additives. The starting materials were non-crystalline Nomex (NCN) and carbon black-dyed Nomex (BN); ACFs were prepared by pyrolysis in Ar followed by $\mathrm{CO}_{2}$ activation at $1073 \mathrm{~K}$ under identical conditions as when crystalline Nomex $(\mathrm{CN})$ was used as precursor in previous work [9]. $\mathrm{N}_{2}(77 \mathrm{~K})$ and $\mathrm{CO}_{2}(273 \mathrm{~K})$ adsorption-desorption isotherms were measured in a volumetric adsorption apparatus NOVA 1200 (Quantachrome). A carbon black (Spheron 6) was used as standard for the $\alpha_{S}$ method. The $\mathrm{CO}_{2}$ adsorption isotherms were measured at low relative pressures $\left(\mathrm{p} / \mathrm{p}^{0}<0.035\right) . X$-ray diffraction $(\mathrm{XRD})$ patterns were obtained in a Siemens D5000 powder diffractometer, using $\mathrm{Cu} \mathrm{K}_{\alpha}$ radiation $\left(\lambda=0.15406 \mathrm{~nm}\right.$ ) and a step size of $0.02^{\circ}$.

$\mathrm{N}_{2}$ adsorption isotherms on $\mathrm{NCN}$-derived materials (not shown) belonged to type I of the BDDT classification, except those for 0 and $5 \% \mathrm{BO}$, which were type II. The slope of the isotherms at $\mathrm{p} / \mathrm{p}^{0}>0.1$ was very low and almost constant for all the BO degrees except at $64 \% \mathrm{BO}$, where there was a significant increase in the slope; this was indeed the only sample exhibiting a (small) adsorption hysteresis loop at high partial pressures of $\mathrm{N}_{2}$, suggesting slight widening of pores at that high $\mathrm{BO}$ degree. $\mathrm{BN}$-derived materials yielded $\mathrm{N}_{2}$ isotherms having many features in common with those from $\mathrm{NCN}$; those corresponding to low $\mathrm{BO}$ degrees exhibited hysteresis at low relative pressures. 
Table 1. XRD structural parameters.

\begin{tabular}{ccccc}
\hline Series & $\mathrm{BO}(\%)$ & $\mathrm{d}_{002}(\mathrm{~nm})$ & $\mathrm{L}_{\mathrm{c}}(\mathrm{nm})$ & $\mathrm{L}_{\mathrm{a}}(\mathrm{nm})$ \\
\hline$N C N$ & 0 & 0.37 & 1.0 & 5.1 \\
& 5 & 0.37 & 1.1 & 5.5 \\
& 13 & 0.37 & 1.0 & 5.3 \\
& 36 & 0.37 & 1.1 & 5.9 \\
& 64 & 0.36 & 1.2 & 7.2 \\
\hline$B N$ & 0 & 0.37 & 1.0 & 4.0 \\
& 7 & 0.37 & 1.1 & 4.7 \\
& 20 & 0.37 & 1.1 & 6.1 \\
& 37 & 0.36 & 1.1 & 6.4 \\
\hline
\end{tabular}

The BET surface area and total pore volume $\left(\mathrm{V}_{\mathrm{p}}\right.$, calculated from the volume of nitrogen adsorbed at $\mathrm{p} / \mathrm{p}^{0} \sim 0.95$; Figure 1) increased with the $\mathrm{BO}$ for the three series of ACFs. At a given BO, no clear difference could be found among the BET surface areas of ACFs prepared from different precursors. The total micropore volume obtained by applying the $\alpha_{\mathrm{s}}$ method to $\mathrm{N}_{2}$ adsorption isotherms $\left(\mathrm{V}_{\mu \mathrm{p} \alpha>1}\right)$ was almost identical to $\mathrm{V}_{\mathrm{p}}$ in the entire BO range, for all the precursors used, with the exception of the sample prepared from $\mathrm{NCN}$ at $64 \% \mathrm{BO}$, confirming the widening of porosity in this material. The similarity between $\mathrm{V}_{\mu \mathrm{p} \alpha>1}$ and $\mathrm{V}_{\mu \mathrm{p} \alpha<1}\left(\right.$ volume of micropores filled at $\alpha_{\mathrm{s}}<1$, i.e., at $\mathrm{p} / \mathrm{p}^{0}<0.4$ ), especially at intermediate and high BO degrees, indicates that most of the porosity created in the studied materials is very narrow.

At low BOs $(\leq 7 \%)$, the adsorbents prepared from NCN exhibited lower values for the textural parameters calculated from $\mathrm{N}_{2}$ adsorption (BET surface area and pore volumes: see $V_{p}, V_{\mu p \alpha<1}$ and $V_{\mu p ~}>1$ in Fig. 1) than for the corresponding $C N$ and BN-derived ACFs. 
However, the micropore volume calculated by application of the Dubinin-RadushkevichKaganer (DRK) equation to $\mathrm{CO}_{2}$ adsorption at $273 \mathrm{~K}\left(\mathrm{~V}_{\mu \mathrm{p} \text { DRK }}\right)$ is similar for ACFs obtained from the three precursors (Fig. 1). This indicates the occurrence in low BO, NCNderived ACFs, of very narrow micropores where $\mathrm{N}_{2}$ adsorption at $77 \mathrm{~K}$ is diffusionrestricted whereas $\mathrm{CO}_{2}$ adsorption at $273 \mathrm{~K}$ is not [10]. The pore width (L), also calculated by applying the DRK equation to the $\mathrm{CO}_{2}$ adsorption data, changed little with the degree of $\mathrm{BO}$ or with the variety of Nomex used as precursor, although there was a slight increase in pore width with increasing $\mathrm{BO}$ for the three series of studied ACFs (it ranged from 0.93 nm to $1.22 \mathrm{~nm})$.

Fig. 1. Evolution of pore volumes as a function of $\mathrm{BO}$ for $\mathrm{CN}, \mathrm{NCN}$ and $\mathrm{BN}$ series of ACFs.

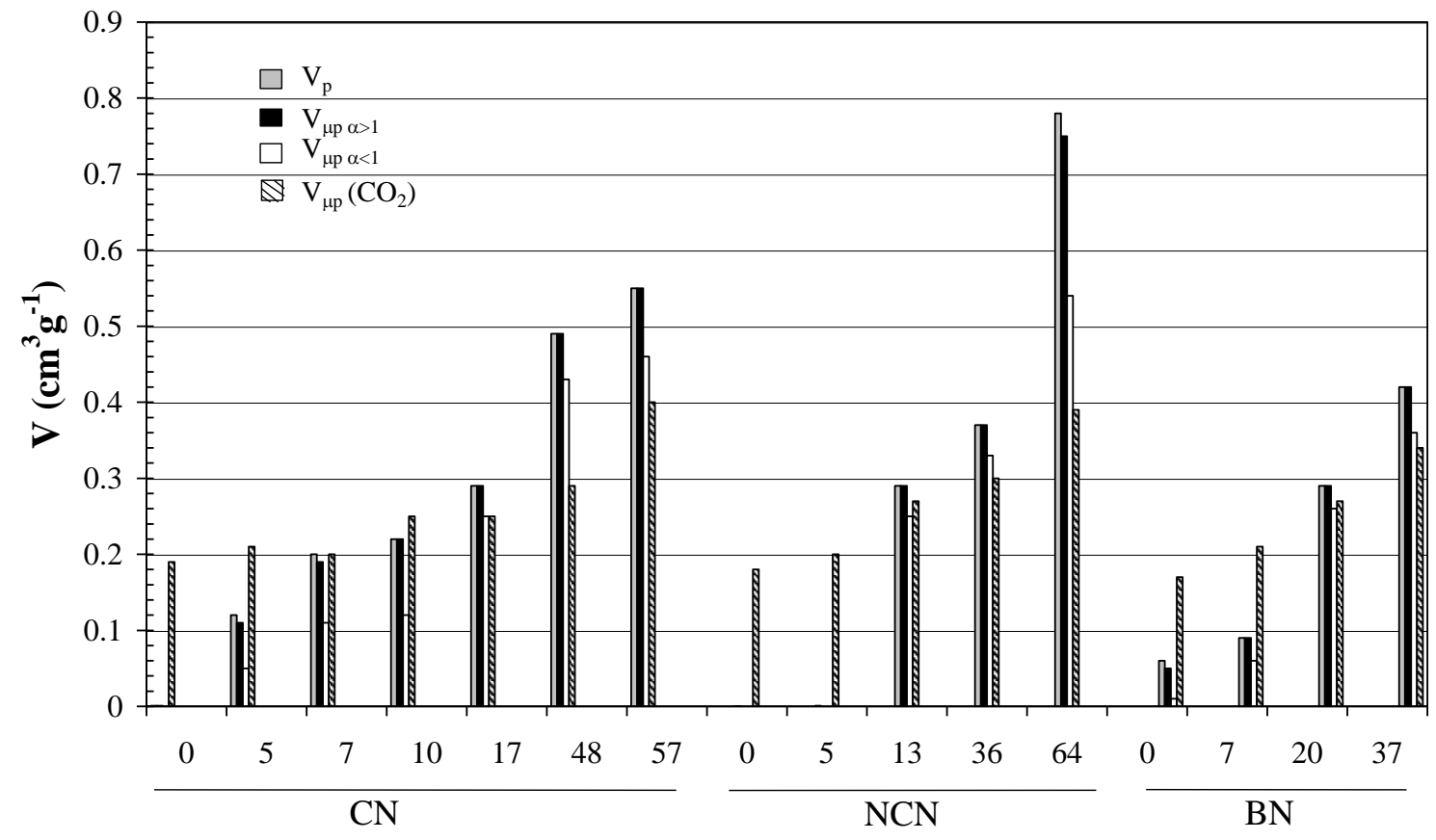

BO (\%) 
As Table 1 shows, the XRD-derived interlayer spacing $\left(\mathrm{d}_{002}\right)$ and average height of pseudographitic stacking units $\left(\mathrm{L}_{\mathrm{c}}\right)$ in materials derived from $\mathrm{NCN}$ and BN are essentially constant and independent of the BO. This is in some contrast with a slight decrease in both parameters with increasing BO observed in the case of $\mathrm{CN}[9,11]$, which was attributed to preferential gasification of the least ordered fractions, expected to be more reactive [12]. However, the average width of the pseudographitic stacking units $\left(\mathrm{L}_{\mathrm{a}}\right)$ increases with increasing BO (Table 1) for both NCN and BN series, as it did in previous work with $\mathrm{CN}[9,11]$. This would suggest that selective gasification, if any, progresses more quickly along the c-axis than along the a-axis for the $\mathrm{NCN}$ and $\mathrm{BN}$-derived materials.

In comparing the measured crystallite size parameters with those in a number of activated carbons from different origins and preparation methods $[14,15]$, Nomex derived ACFs exhibit an intermediate degree of structural order on the basis of $\mathrm{d}_{002}$ and $\mathrm{L}_{\mathrm{c}}$, and slightly higher on the basis of $\mathrm{L}_{\mathrm{a}}$. In comparison with chars and ACFs from Kevlar [poly ( $p$-phenylene terephthalamide)] [13], lower $\mathrm{d}_{002}$, $\mathrm{L}_{\mathrm{c}}$ and $\mathrm{L}_{\mathrm{a}}$ values are systematically obtained with all Nomex varieties; the possibility of this being related to the lower crystallinity degree of Nomex regarding Kevlar remains open to discussion.

In summary, one can conclude that the porous texture and crystal structure of Nomex-derived ACFs are little dependent on the crystallinity degree of Nomex or the presence therein of carbon black as a dying additive, porosity being chiefly associated to the $\mathrm{BO}$. The lack of dependence of texture and structure on precursor characteristics suggests that used Nomex and/or its by-products can substitute 
virgin Nomex as a precursor for ACFs, thus providing an interesting recycling route for these residues.

\section{Acknowledgements}

Financial support from CICYT (project 1FD97-1915), and financial (project PB-MAT9704) and fellowship support from II PRI Asturias are gratefully acknowledged. The authors thank their colleagues Javier Fernández and Celina Blanco (DuPont-Asturias) for providing the various Nomex samples.

\section{References}

1. J.J. Freeman, J.B. Tomlinson, K.S.W. Sing, C.R. Theocharis, Carbon 31 (1993) 865.

2. J.J. Freeman, J.B. Tomlinson, K.S.W. Sing, C.R. Theocharis, Carbon 33 (1995) 795.

3. F. Stoeckli, T.A. Centeno, A.B. Fuertes, J. Muñiz, Carbon 34 (1996) 1201.

4. A. Martínez-Alonso, M. Jamond, M. Montes-Morán, J.M.D. Tascón, Microp. Mater. 1 (1997) 303.

5. J.B. Tomlinson, J.J. Freeman, K.S.W. Sing, C.R Theocharis, Carbon 33 (1995) 789.

6. P.J.M. Carrott, R.A. Roberts, K.S.W. Sing, Carbon 27 (1989) 85.

7. A. McInally, R.R. Mather, K.S.W. Sing, in: F. Rodríguez Reinoso, J. Rouquerol, K.S.W. Sing (Eds.), Characterization of Porous Solids II, Elsevier, Amsterdam, 1991, p. 409.

8. Y.Z. Zhang, M.Z. Wang, B.J. Zhang, J. Mater. Sci. 32 (1997) 609.

9. M.C. Blanco López, A. Martínez-Alonso, J.M.D. Tascón, Microp. Mesop. Mater. 34 (2000) 171.

10. J. Garrido, A. Linares-Solano, J.M. Martín-Martínez, M. Molina-Sabio, F. RodríguezReinoso, R. Torregrosa, Langmuir 3 (1987) 76. 
11. F. Rodríguez-Reinoso, M. Molina-Sabio, Carbon 32 (1992) 1111.

12. M. C. Blanco López, A. Martínez-Alonso and J.M.D. Tascón, Carbon 38 (2000) 1177.

13. A. Cuesta, A. Martínez-Alonso, J.M.D. Tascón and R.H. Bradley, Carbon 35 (1997) 967.

14. A. Cuesta, P. Dhamelincourt, J. Laureyns, A. Martínez-Alonso and J.M.D. Tascón, J. Mater. Chem. 8 (1998) 2875.

15. A. Cuesta, Ph.D. Thesis, University of Oviedo, Oviedo, Spain, 1994. 